\title{
BMJ Open Perceived bullying among Norwegian doctors in 1993, 2004 and 2014-2015: a study based on cross-sectional and repeated surveys
}

Judith Rosta, Olaf G Aasland

To cite: Rosta J, Aasland OG. Perceived bullying among Norwegian doctors in 1993 , 2004 and 2014-2015: a study based on cross-sectional and repeated surveys. BMJ Open 2018;8:e018161. doi:10.1136/ bmjopen-2017-018161

- Prepublication history for this paper is available online. To view these files, please visit the journal online (http://dx.doi. org/10.1136/bmjopen-2017018161).

Received 9 June 2017 Revised 27 September 2017 Accepted 20 November 2017

Check for updates

Institute for Studies of the Medical Profession, Oslo, Norway

Correspondence to Dr Judith Rosta; judith.rosta@legeforeningen.no

\section{ABSTRACT}

Objectives To examine 12-month prevalence of perceived bullying at work for doctors in different job categories and medical disciplines in 1993, 2004 and 2014-2015, and personality traits, work-related and health-related factors associated with perceived workplace bullying.

Design Cross-sectional questionnaire surveys in 1993, 2004 and 2014-2015 where the 2004 and the 2012-2015 samples are partly overlapping.

Setting Norway.

Participants Response rates were $72.8 \%$ (2628/3608) in $1993,67 \%$ (1004/1499) in 2004 and $78.2 \%$ (1261/1612) in 2014-2015. 485 doctors responded both in 2004 and 2014-2015.

Outcome measure Perceived bullying at work from colleagues or superiors at least a few times a month during the last year.

Results Between the samples from 1993, 2004 and 2014-2015, there were no significant differences in the prevalence of perceived bullying at work. More senior hospital doctors and surgeons reported being bullied. Doctors with higher scores on the personality trait neuroticism were more likely to perceive bullying, as were female doctors, doctors with poor job satisfaction and poor self-rated health.

Conclusions The fraction of doctors who experienced bullying at work was stable over a 20 -year period. Psychological, psychosocial and cultural factors are predictors of perceived bullying.

\section{INTRODUCTION}

The negative effects of workplace bullying on both the individual and the organisational level are well documented. Bullying is often associated with suboptimal health and poor job satisfaction, as well as frequent job change and increased absenteeism. ${ }^{1-3}$ It is also shown that poor health and low job satisfaction of doctors may affect patient safety and treatment outcomes. ${ }^{4}$ Despite these negative effects, work place bullying among doctors has not been well studied in Norway.

International variations in the prevalence of workplace bullying are large. On average, $5 \%$ of the respondents in the sixth European

\section{Strengths and limitations of this study}

The study describes the prevalence of perceived bullying at work among doctors over a 20 -year period.

- The data allow for generalisation to the whole doctor population in Norway.

- Analyses are based on self-reported questionnaire data with the possibility of both overestimation and underestimation.

Working Condition Survey 2015 comprising all the European Union (EU)-28 countries reported being subjected to bullying or harassment during the last 12 months. ${ }^{5}$ Norway was below the EU average. ${ }^{6}$ In national studies in Norway, $2 \%-3 \%$ of employees had been bullied at work at least once a month, with no significant differences within age or gender. Between occupational groups, service-related occupations (waiters, craftspersons, military, police, healthcare and social care) experience bullying more than average. ${ }^{78}$

In cross-sectional studies from Europe, ${ }^{9-13}$ $\mathrm{USA}^{14-16}$ and Australia, ${ }^{17}$ the prevalence of experienced bullying at work for diverse groups of doctors range from $16 \%$ to $76 \%$ depending on study design and method of assessment. A cross-national comparison between four European university hospitals in 2004-2005 showed lower prevalence of degrading experiences including bullying at the workplace during the previous 6 months for doctors in Trondheim/Norway $(10.5 \%)$, than in Reykjavik/Iceland (12.7\%), in Stockholm/Sweden (13.8\%) and in Padova/Italy $(20.2 \%) .^{18}$

According to the work environmental hypothesis, poor psychosocial conditions like dissatisfaction, stress or high levels of conflict play important roles in generating workplace bullying. ${ }^{19}$ Associations between individual personality traits and workplace bullying are 
also documented, but a cause-and-effect relationship is complex. ${ }^{20}$

In Norway, many studies, including hospital staff ${ }^{21}$ and nurses, ${ }^{2}$ have addressed bullying at the workplace, but none have examined the experience of doctors based on a nationwide representative dataset over a 20-year period.

Since 1993, the Institute for Studies of the Medical Profession (LEFO) has regularly surveyed a representative sample of active doctors in Norway (www.legeforsk. org). The surveys in 1993, 2004 and 2014-2015 included identical questions on perceived bullying at work. It is therefore possible to reliably describe changes during this period.

In this article, we focus on the prevalence of perceived bullying at work for Norwegian doctors in various types of job and for hospital doctors practising in different medical disciplines in 1993, 2004 and 2014-2015. We also investigate to what extent being bullied is associated with other work-related and health-related factors. In addition, we explore the possible association between perceived bullying and two major personality traits: introversion-extraversion and neuroticism.

\section{MATERIALS AND METHODS Design and participants}

In Norway, doctors' health and working conditions have been followed since 1992 by the Institute for Studies of the Medical Profession through a comprehensive research programme.

In 1993, a random sample of 9266 active doctors in Norway were invited to take part in a postal survey on doctors' health, working conditions and quality of life, and $6672(72 \%)$ agreed. From a pool of 16 different questionnaires, each doctor received four, one basic to all and the three others with different themes, randomly distributed according to a weighted system. The intention was to achieve better statistical power through a random pattern of missing responses in the total database. ${ }^{22}$ See Aasland $e t a l^{23}$ for a detailed description of this overlapping questionnaire design. The data used in this article are from a representative subsample of 3608 doctors who received a questionnaire about organisation of work and work environment including item on perceived bullying at work.

An additional randomly selected group of 2000 doctors were invited to participate in a longitudinal study, and 1272 (64\%) agreed. ${ }^{22}{ }^{23}$ Since 1994, this sample has been followed through biannual postal questionnaires, while retired doctors were successively replaced by younger colleagues. These data constitute a set of unbalanced panel data, ${ }^{24}$ with variation in the number of observations for each respondent. ${ }^{25} 26$ The 2004 questionnaire $(\mathrm{n}=1499)$ and the 2014-2015 questionnaire $(\mathrm{n}=1612)$ both contained the same question on perceived bullying at work as in the 1993 questionnaire.

Informed consent was obtained from all participants in the three surveys, as well as an exemption from specific review of the individual surveys from the Regional Committee for Medical Research Ethics.

\section{Variables}

Response variable

Perceived bullying at work was assessed with the question, 'Have you during the last year been subjected to vexation or uncomfortable teasing (bullying) from colleagues or superiors?' Response categories were: no, yes-a few times a month, yes-about once a week, yes—a few times a week and yes-daily or almost daily. For most of the statistical analyses in this article, the categories were collapsed into 'no' and 'yes' (ie, from a few times a month to daily or almost daily). This item corresponds to similar questions used in other surveys on psychosocial working conditions in the Norwegian working population, ${ }^{722}$ where it also pertains to last year, and with the additional explanation that 'vexation or uncomfortable teasing' means bullying. ${ }^{27}$

\section{Effect variables}

Numerous associations with workplace bullying have been reported, for example, poor mental or physical health, personality traits and poor working conditions. The present study includes the following items:

Self-rated health was measured in 2014-2015 by the question 'In general, would you say your health is: very good, good, average, poor'.

Sickness absence was measured in 2014-2015 with a single question, "How many days of sickness absence have you taken during the past 12 months?" The reported number of sickness absence days was recoded into four levels: 0 days, 1-3 days, 4-99 days and 100 days or more. ${ }^{28}$

Job satisfaction was measured with the 'Job Satisfaction Scale' of Warr et al. ${ }^{29}$ It includes 10 items that scored on a Likert scale from 1 (very dissatisfied) to 7 (very satisfied). The items were added together into a composite mean job satisfaction scale with possible values from 10 to 70 .

Two personality dimensions, extraversion-introversion and neuroticism, were measured with the 'Eysenck Personality Inventory'. Each dimension is based on 10 yes or no questions, giving a range from 0 to $10 .{ }^{30}$ A subset of the members of the repeated surveys had completed the inventory in 2002.

\section{Group variables}

\section{Job categories}

1. Doctors in hospital management positions (medical superintendent, head of department, chief senior consultant, head of unit, senior consultant, head of section).

2. Senior hospital consultants.

3. Specialty registrars.

4. General practitioners (GPs).

5. Specialists working in private practice.

6. Community medical officers (district medical officer, senior district medical officer, nursing home medical 
officer, visiting medical officer, doctor at infant welfare clinic, community GP).

7. Doctors in academia (professor, associate professor, research fellow and researcher).

8. Doctors in administrative positions (county medical officer, medical advisor, chief medical officer).

9. Other key job categories.

\section{Medical disciplines}

For the purpose of this study, the 45 different disciplines are collapsed into five categories:

1. General (internal) medicine disciplines (general practice, paediatrics, haematology, endocrinology, gastroenterology, physical medicine and rehabilitation, geriatrics, cardiology, dermatology, internal medicine, communicable diseases, respiratory medicine, neurology, oncology, nephrology, rheumatology).

2. Surgical disciplines (anaesthesiology, paediatric surgery, cardiothoracic and endocrine surgery, obstetrics and gynaecology, gastroenterological surgery, general surgery, vascular surgery, maxillofacial surgery, neurosurgery, orthopaedic surgery, plastic surgery, thoracic surgery, urology, otorhinolaryngology, ophthalmology).

3. Laboratory disciplines (immunology and transfusion medicine, clinical pharmacology, clinical neurophysiology, medical biochemistry, medical genetics, medical microbiology, nuclear medicine, pathology, radiology).

4. Psychiatry (psychiatry, child and adolescent psychiatry, substance abuse and addiction medicine, community medicine).

5. Other.

Other variables were Regional Health Authority (North, Central, West and Southeast), age and gender.

\section{Analysis}

Using proportions with 95\% CIs we explored possible changes over time in the prevalence of perceived bullying by comparing the three cross-sectional datasets from 1993, 2004 and 2014-2015, respectively. We also looked

Table 1 The 12-month prevalence of perceived bullying at work from colleagues or superiors for Norwegian doctors in the cross-sectional data from 1993, 2004 and 2014-2015

\begin{tabular}{llll}
\hline & $\begin{array}{l}\mathbf{1 9 9 3} \\
\mathbf{\%}(\mathbf{n})\end{array}$ & $\begin{array}{l}\mathbf{2 0 0 4} \\
\mathbf{\%}(\mathbf{n})\end{array}$ & $\begin{array}{l}\mathbf{2 0 1 4 - 2 0 1 5} \\
\mathbf{\%}(\mathbf{n})\end{array}$ \\
\hline No & $94.3(2300)$ & $92.7(677)$ & $93.0(1004)$ \\
$\begin{array}{l}\text { Yes, a few times } \\
\text { a month }\end{array}$ & $4.5(109)$ & $5.2(38)$ & $5.5(59)$ \\
$\begin{array}{l}\text { Yes, about ones a } \\
\text { week }\end{array}$ & $0.6(15)$ & $1.0(7)$ & $0.6(7)$ \\
$\begin{array}{l}\text { Yes, a few times } \\
\text { a week }\end{array}$ & $0.3(8)$ & $0.8(6)$ & $0.6(7)$ \\
$\begin{array}{l}\text { Yes, daily or } \\
\text { almost daily }\end{array}$ & $0.3(7)$ & $0.3(2)$ & $0.3(3)$ \\
\hline
\end{tabular}

at potential changes among the 485 who responded both in 2004 and 2014-2015. General linear models with age and gender as covariates were used to describe the associations between perceived bullying and personality traits in the cross-sectional data. Based on cross-sectional data from 2014 to 2015, a logistic regression model was used to assess the simultaneous effect of gender, age, job satisfaction, self-rated health and sickness absence on perceived bullying. Units with missing data were excluded. Predictive Analytics Software Statistics V.23 was used for the analyses.

\section{RESULTS}

\section{Respondents}

\section{Representativity and response rates}

Both the respondents of the cross-sectional survey in 1993 and the longitudinal surveys in 2004 and 2014-2015 were nearly representative of the total doctor work force in terms of age, gender and main job categories (as described in previous studies). ${ }^{23} 2526$

The response rates were $72.8 \%(2628 / 3608)$ in 1993 , $67 \%(1004 / 1499)$ in 2004 and $78.2 \%(1261 / 1612)$ in 2014-2015. The numbers of respondents with data on all variables (perceived bullying, gender, age and job category) were 2439 in 1993, 730 in 2004 and 1080 in 20142015. Four hundred and eighty-five doctors responded both in 2004 and 2014-2015.

Subsamples of the longitudinal surveys had completed the Eysenck Personality Inventory in 2002: 614 of 730 respondents in 2004 and 532 of 1080 in 2014-2015. Since personality is regarded a trait, we combined data from 2002 with 2004 and 2014-2015.

Gender, age and job characteristics of doctors in the crosssectional data from 1993, 2004 and 2014-2015

The proportion of women in our samples increased from $27.9 \%(n=680)$ in 1993 to $31.5 \%(n=230)$ in 2004 and further to $43.1 \%(\mathrm{n}=465)$ in $2014-2015$. The mean age was 42.2 years (95\% CI 41.8 to 42.6 ) in 1993, 54.3 years $(95 \%$ CI 53.7 to 54.9$)$ in 2004 and 48.5 years $(95 \%$ CI 47.9 to 49.2 ) in 2014-2015, when younger doctors had been included in the sample. The majority of respondents worked full time in hospitals (data not shown).

Gender, age and job characteristics of doctors in the repeated data from 2004 and 2014-2015

Among the 485 doctors who responded both in 2004 and $2014-2015,31.8 \%(\mathrm{n}=154)$ were women and $68.2 \%$ $(\mathrm{n}=331)$ were men. The mean age was 46.6 years $(95 \%$ CI 45.9 to 47.3 ) in 2004 and 56.8 years (95\% CI 56.1 to 57.5) in 2014-2015. In 2004 and 2014-2015, about every second doctor worked in hospitals. The rest were either GPs or had other jobs like administration or private specialist practice (data not shown). 
Table 2 Group differences in 12-month prevalence of perceived bullying at work from colleagues or superiors at least few times a month for Norwegian doctors in the cross-sectional data from 1993, 2004 and 2014-2015

\begin{tabular}{|c|c|c|c|c|c|c|}
\hline & \multicolumn{2}{|r|}{$1993(n=2439)$} & \multicolumn{2}{|r|}{$2004(n=730)$} & \multicolumn{2}{|c|}{$2014-2015(n=1080)$} \\
\hline & $n$ & $\%(95 \% \mathrm{Cl})$ & $\mathbf{n}$ & $\%(95 \% \mathrm{Cl})$ & $\mathrm{n}$ & $\%(95 \% \mathrm{Cl})$ \\
\hline All doctors & 139 & 5.7 (4.8 to 6.6$)$ & 53 & 7.3 (5.4 to 9.2 ) & 76 & 7.0 (4.5 to 8.5$)$ \\
\hline \multicolumn{7}{|l|}{ Gender } \\
\hline Females & 57 & $8.3(6.5$ to 10.7$)$ & 11 & 4.8 (3.0 to 8.4$)$ & 43 & $9.2(6.6$ to 11.8$)$ \\
\hline Males & 82 & 4.7 (3.8 to 5.8$)$ & 42 & 8.4 (6.3 to 11.2$)$ & 33 & 5.4 (3.6 to 7.2$)$ \\
\hline \multicolumn{7}{|l|}{ Age by years } \\
\hline $25-35$ & 31 & 5.6 (3.9 to 7.8$)$ & 0 & $0.0(-)$ & 11 & 6.7 (3.8 to 11.6$)$ \\
\hline $36-45$ & 56 & 5.8 (4.5 to 7.5$)$ & 11 & 10.9 (6.2 to 18.5$)$ & 25 & 8.5 (5.8 to 12.3$)$ \\
\hline $46-55$ & 38 & 6.0 (4.4 to 8.2$)$ & 16 & $7.7(4.8$ to 12.1$)$ & 20 & 8.1 (5.3 to 12.1$)$ \\
\hline $56-65$ & 13 & 5.3 (3.1 to 8.9$)$ & 20 & 5.8 (3.8 to 8.9$)$ & 19 & 6.1 (4.0 to 9.4$)$ \\
\hline $66-69$ & 1 & $2.1(0.4$ to 11.1$)$ & 6 & $10.2(4.7$ to 20.5$)$ & 1 & $1.6(0.3$ to 8.3$)$ \\
\hline \multicolumn{7}{|l|}{ Job positions } \\
\hline Specialty registrars & 67 & $7.2(5.7$ to 9.1$)$ & 6 & $5.2(2.4$ to 10.9$)$ & 11 & 6.5 (2.8 to 10.2$)$ \\
\hline Senior hospital consultants & 11 & 14.3 (8.2 to 23.8$)$ & 19 & $10.2(6.6$ to 15.4$)$ & 34 & 9.7 (6.6 to 12.8$)$ \\
\hline $\begin{array}{l}\text { Doctors in hospital management } \\
\text { positions }\end{array}$ & 1 & 11.1 (2.0 to 43.5$)$ & 9 & 9.6 (5.1 to 17.2$)$ & 10 & $9.7(4.0$ to 15.4$)$ \\
\hline Community medical officers & 27 & 5.7 (4.0 to 8.2 ) & 2 & 6.5 (1.8 to 20.7$)$ & 0 & $0.0(-)$ \\
\hline General practitioners & 6 & 2.4 (1.1 to 5.2$)$ & 8 & 4.3 (2.2 to 8.3$)$ & 9 & $4.0(1.5$ to 6.6$)$ \\
\hline Specialists in private practice & 1 & $9.1(1.6$ to 37.7$)$ & 2 & $4.3(1.2$ to 14.2$)$ & 0 & $0.0(-)$ \\
\hline Doctors in academia positions & 7 & 7.3 (3.6 to 14.3$)$ & 3 & $11.5(4.0$ to 29.0$)$ & 7 & $11.3(3.4$ to 19.2$)$ \\
\hline Doctors in administrative positions & 1 & 16.7 (3.0 to 56.4$)$ & 1 & $11.1(2.0$ to 43.5$)$ & 2 & $7.1(-2.4$ to 16.6$)$ \\
\hline \multirow[t]{3}{*}{ Other } & 18 & 3.0 (1.9 to 4.8$)$ & 3 & 7.9 (2.7 to 20.8$)$ & 3 & $8.8(-0.7$ to 18.3$)$ \\
\hline & \multicolumn{2}{|r|}{$1993(n=1014)$} & \multicolumn{2}{|r|}{$2004(n=395)$} & \multicolumn{2}{|c|}{ 2004-2015 (n=618) } \\
\hline & $n$ & $\%(95 \% \mathrm{Cl})$ & $\mathbf{n}$ & $\%(95 \% \mathrm{Cl})$ & $\mathbf{n}$ & $\%(95 \% \mathrm{Cl})$ \\
\hline All hospital doctors ${ }^{\star}$ & 79 & 7.8 (6.3 to 9.6$)$ & 34 & 8.6 (6.2 to 11.8$)$ & 54 & 8.7 (6.4 to 10.8$)$ \\
\hline Internal medicine & 15 & 4.9 (3.0 to 8.0$)$ & 11 & 7.5 (4.2 to 12.9$)$ & 18 & $6.9(4.4$ to 10.7$)$ \\
\hline Laboratory medicine & 5 & 7.9 (3.4 to 17.3$)$ & 5 & 8.9 (3.9 to 19.3$)$ & 6 & 8.5 (3.9 to 17.2$)$ \\
\hline Surgery & 25 & 11.1 (7.6 to 15.9$)$ & 13 & 11.7 (7.0 to 19.0$)$ & 15 & 9.3 (5.7 to 14.8$)$ \\
\hline Psychiatry & 6 & 5.2 (2.4 to 10.8$)$ & 4 & 5.4 (2.1 to 13.1$)$ & 12 & 10.3 (6.0 to 17.2$)$ \\
\hline Other & 28 & $9.2(6.5$ to 13.0$)$ & 1 & 14.3 (2.6 to 51.3$)$ & 3 & $30.0(10.8$ to 60.3$)$ \\
\hline
\end{tabular}

*Hospital doctors include specialty registrars, senior hospital doctors and doctors in hospital management positions. Missing for medical disciplines in datasets: $n=11$ in 1993, $n=46$ in 2004, $n=10$ in 2014-2015.

Prevalence of perceived bullying at work in the crosssectional data from 1993, 2004 and 2014-2015

Table 1 shows consistent levels of perceived bullying from colleagues or superiors among all doctors over the 20-year period.

Group differences in the prevalence of perceived bullying at work in the cross-sectional data from 1993, 2004 and 2014-2015

Table 2 shows the prevalence of perceived bullying at work from colleagues or superiors at least a few times a month within the last 12 months by gender, age groups and main job positions among all doctors, and by medical disciplines among hospital doctors in 1993, 2004 and 2014-2015.
There were no significant changes over time among all doctors or within different job positions, medical disciplines, age groups or women. A significant increase was for men in 2004.

Regarding job positions, the prevalence of perceived bullying at work was higher for senior hospital consultants and for doctors in hospital management positions than for specialty registrars, GPs and specialist in private practice. In 1993, GPs reported significantly lower prevalence of perceived bullying than specialty registrars and senior hospital doctors.

Across medical disciplines in hospital, the highest prevalence of perceived bullying at work was found among doctors in surgery and laboratory disciplines 


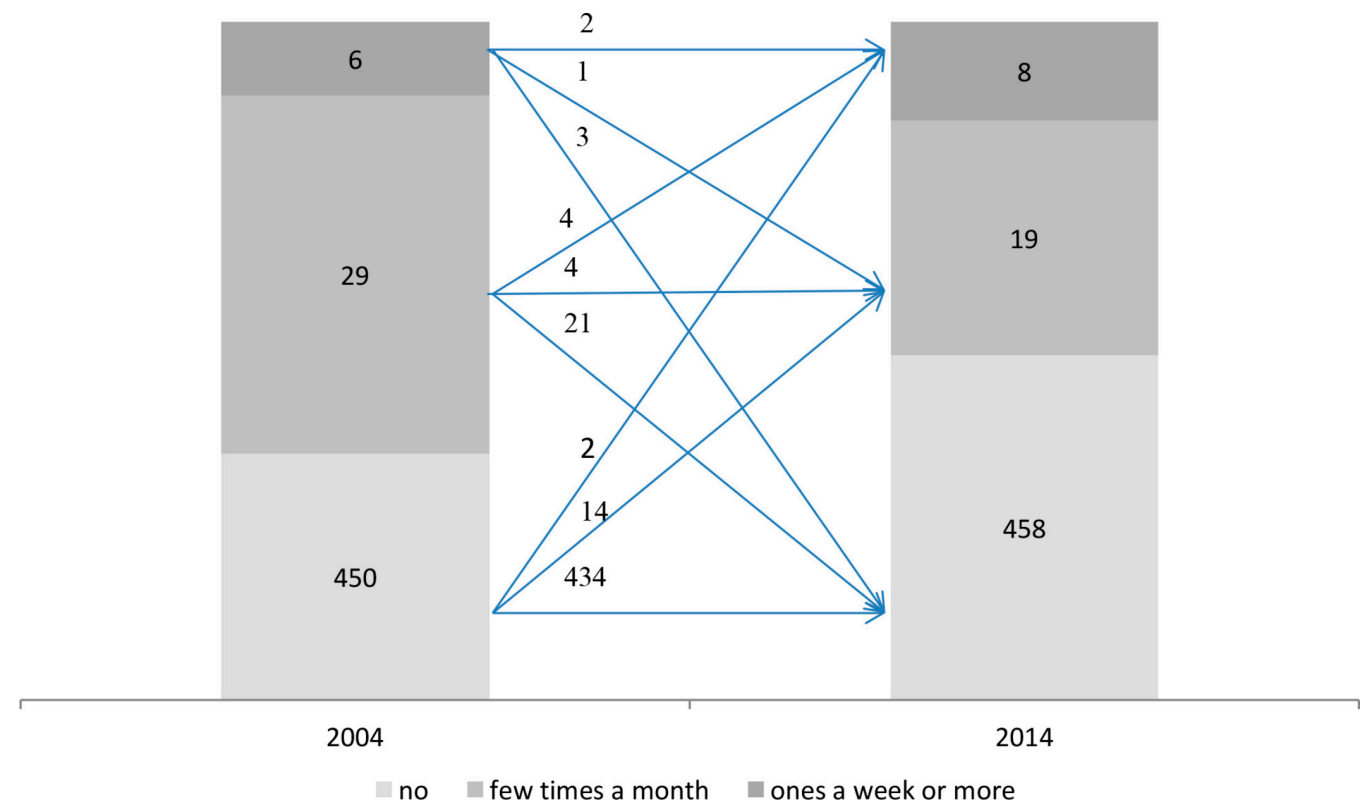

Figure 1 Changes in perceived bullying at work in the repeated measures from 2004 and 2014-2015 (n=485).

in 1993 and 2004, and in surgery and psychiatry in 2014-2015.

Among hospital doctors in 2014-2015, no significant differences in perceived bullying were found across the four Regional Health Authorities (data not shown).

\section{Changes in perceived bullying at work in the repeated measures from 2004 and 2014-2015}

Figure 1 illustrates how the prevalence of perceived bullying at work changed from 2004 to 2014-2015 among the 485 doctors who answered at both points in time. There was a non-significant decrease in perceived bullying at work at least few times a months from $7.2 \%$ (95\% CI 5.2 to $9.9 ; n=35)$ in 2004 to $5.6 \%$ (95\% CI 3.9 to $8.0 ; \mathrm{n}=27)$ in $2014-2015$.

\section{Perceived bullying at work and personality traits in the cross-} sectional data

To explore the associations between perceived bullying and personality traits, we performed multivariate logistic regression analyses for the cross-sectional samples in 2004 $(\mathrm{n}=614)$ and 2014-2015 $(\mathrm{n}=532)$. Controlled for gender and age, neuroticism was a significant predictor in the cross-sectional samples from 2004 (OR 1.28, 95\% CI 1.13 to 1.44$)$ and 2014-2015 (1.24, 1.07 to 1.45$)$. Introversionextraversion showed no effect (data not shown).

Associations between perceived bullying at work and possible effect variables in the cross-sectional data from 2014-2015

Table 3 lists the included effect variables, and summarises the univariate and multivariate analyses of the variables on perceived bullying at work from colleagues or superiors at least a few times a month within the last year for all doctors. Being women, having lower job satisfaction and lower levels of self-rated health were significant univariate and multivariate predictors.

\section{DISCUSSION}

\section{Main findings}

The prevalence of perceived bullying at work did not change significantly neither in the cross-sectional samples from 1993 to 2004 and further to 2014-2015, nor in the repeated measures from 2004 to 2014-2015. More senior hospital doctors and doctors in surgery reported being bullied over the study period. Association of perceived bullying at work with self-reported health, job satisfaction and neuroticism was confirmed.

\section{Comparison with other studies}

Differences in methodology regarding data collection, sample characteristics and measurements limit direct cross-national comparisons. The perception of having experienced bullying at work, however, seems to be lower in our sample in Norway (table 2) compared with residents/fellows in USA (48\%), ${ }^{14}$ junior doctors in Germany $(13 \%-16 \%),{ }^{12}$ doctor-researchers in the UK $(42 \%-$ $75 \%){ }^{9}$ surgery trainees and consultants in Australia $(47 \%),{ }^{17}$ GPs in Lithuania $(30 \%)^{11}$ and Canada (79\%). ${ }^{16}$

Perceived bullying at work for Norwegian specialty registrars at all three time points was slightly lower than for senior hospital consultants and doctors in hospital management position. The opposite was observed among surgery trainees versus consultant surgeons in Australia, and among doctors in postgraduate positions 1 versus levels 2-8 in hospital settings in the USA, while no such differences were found in the UK. ${ }^{13} 1417$ The higher prevalence for doctors in surgery and academic positions is more consistent. ${ }^{9131731}$

A study from Germany describes the 12-month prevalence for experienced bullying over time. As opposed to our findings, this study reports a slightly increasing prevalence among junior hospital doctors in Germany, from 
Table 3 List of effect variables, univariate and multivariate analyses of the variables on perceived bullying at work from colleagues or superiors at least a few times a month for all doctors in the cross-sectional data from 2014 to 2015 ( $n=1053$ )

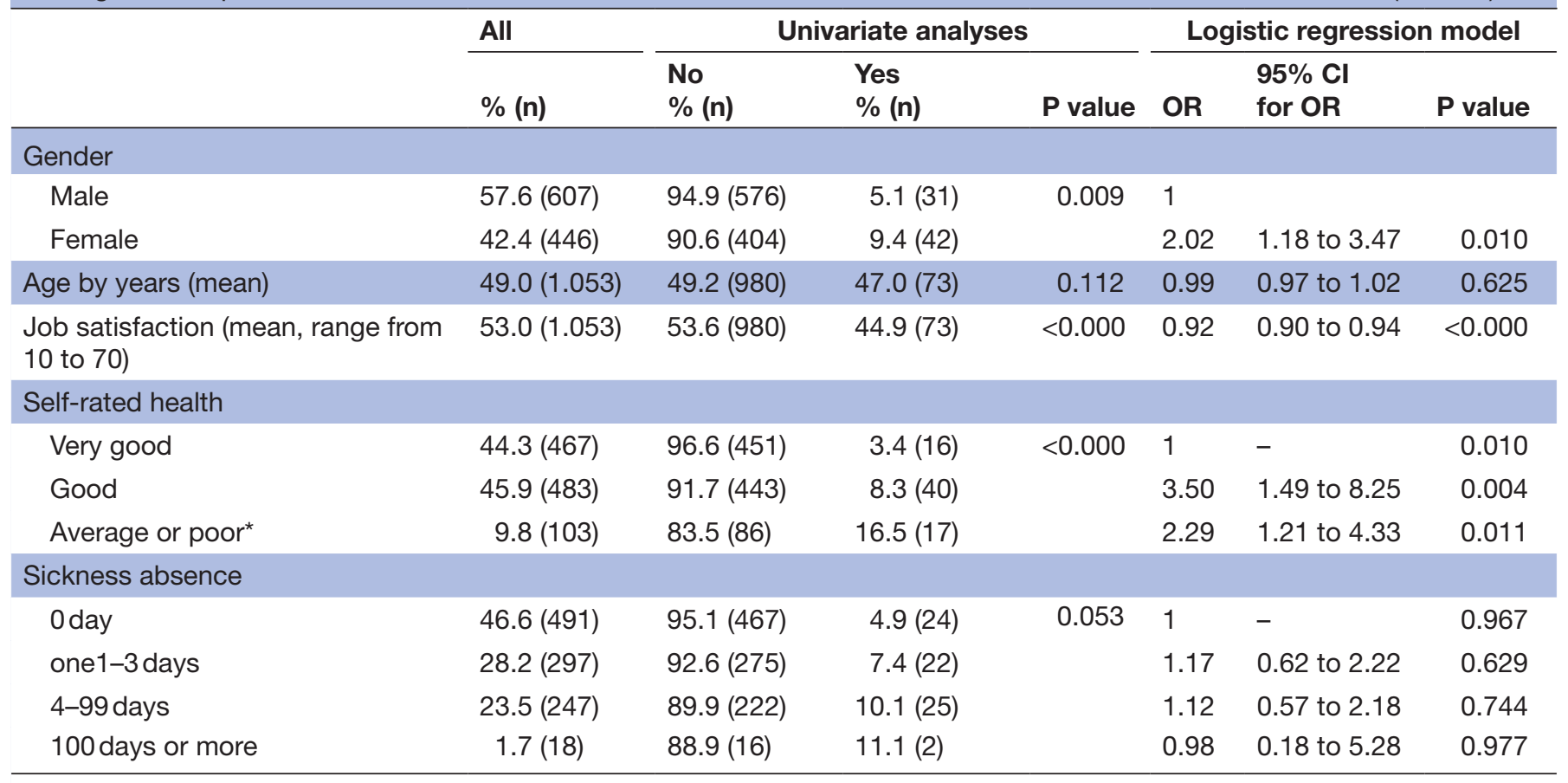

*Categories of self-rated health 'average' and 'poor' collapsed into 'average or poor', because of very low response of 'poor' ( $\mathrm{n}=1)$.

$12.9 \%$ at baseline in 2004 to $14.9 \% 1$ year after baseline, and further to $15.9 \% 3$ years after baseline. ${ }^{12}$

Our findings add to other Norwegian studies suggesting that workers in the health and social sectors are more at risk for reporting experienced bullying at work. ${ }^{78}$ In our survey from 1993, 2004 and 2014-2015, about 6\%-7\% of doctors reported perceived bullying at work from colleagues or superiors at least a few times a month within the last 12 months, compared with $2 \%-3 \%$ in the general working population in the period 1989-2013. ${ }^{727}$

In our cross-sectional data, neuroticism was positively associated with reporting perceived bullying experiences, which is also found in several other studies. ${ }^{2032}$

In our multivariate model, perceived bullying at work at least few times a month within the last year was associated with both lower level of self-reported health and poorer job satisfaction, but not with sickness absence. These results are in agreement with recent meta-analyses on health-related and job-related outcomes of bullying at work. $^{133}$

\section{Explanation of results}

The work environmental hypothesis emphasises the importance of psychosocial work factors on workplace bullying. It implies that poor psychosocial working conditions characterised by dissatisfaction, stress and unpredictable tasks can lead to conflicts, which in turn may develop into bullying. ${ }^{19}$ Workplaces with high levels of conflict between workers were found to have increased risk of bullying. ${ }^{27}$ Victims of bullying were also showed to be more dissatisfied with several other psychosocial factors in the work environment. ${ }^{34}$ On the other hand, personality traits like neuroticism was associated with the perception of being bullied. Doctors who scored high on neuroticism were also more reactive to stress ${ }^{35}$ and more likely to interpret situations as threatening. ${ }^{20}$

Thus, the lower prevalence of perceived workplace bullying at the population level, and explicitly in the Norwegian medical profession compared with some other countries, can partly be explained by variations in psychosocial working conditions.

Good working environment is part of a work culture in Norway. ${ }^{36}$ In the Organisation for Economic Co-operation and Development study across 38 countries from 2016 on Better Life Index, the average level of life satisfaction was highest in Norway, suggesting strong social cohesion. ${ }^{37}$ In the Eurofound study across 28 countries from 2015 on working environment, there was a more positive picture of psychosocial and organisational working conditions in Norway, for example, the scores for being 'very satisfied or satisfied' in the main job, and being 'always or almost all the time' treated fairly at the workplace, were higher in Norway (93\%; 94\%) compared with for example Germany (89\%; 90\%), Sweden $(85 \%$; 87\%), Italy $(83 \% ; 84 \%)$, UK $(90 \% ; 85 \%)$ and Lithuania $(83 \%$; $76 \%) .{ }^{5}$ In the 2005 European working conditions survey, Norway showed the second highest level of satisfaction. ${ }^{38}$ In studies of the medical profession, doctors in Norway, compared with some other countries reported lower stress levels, ${ }^{39}$ better work-home balance, lower working time, ${ }^{2640}$ a higher level of job satisfaction ${ }^{3941-43}$ and lower prevalence for self-reports of perceived bullying at work, ${ }^{18}$ suggesting a better work atmosphere in Norway. 
Differences in cultural and psychosocial environmental factors across occupational groups in Norway may account for variations in perception of experienced bullying. In the 2013 Living Condition Survey of the Norwegian working population, doctors were the occupational group that scored highest on the scales of psychosocial risk factors at work including work-home unbalance, long working weeks, night works, frequent reorganisations at workplace and high effort at work. ${ }^{7}$ In a previous nationwide survey, the medical occupations scored second highest on a scale of conflicts at work. About 6 of 10 doctors reported conflicts both between leader and employees and between employees. ${ }^{27}$ Current studies underline the higher workload and lower workhome balance in the doctor work force compared with several occupations in Norway. ${ }^{25}$ In addition, studies points to the importance of cultural factors such as the traditional hierarchical structures and teaching methods in the medical profession that might influence the development of bullying. ${ }^{445}$

Doctors are not a homogenous group. We found that doctors working in public sector hospitals reported workplace bullying more frequently than doctors working as GPs or as private practice specialist. This finding is consistent with a national survey suggesting a higher prevalence of work conflicts in public as opposed to private settings. ${ }^{27}$ Previous Norwegian studies have also shown that hospital doctors experience more psychosocial work stress and are less satisfied with several aspects of the job conditions than are GPs and private practice specialists. ${ }^{28} 46$

The present study documents no significant changes in the perceived bullying at work from 1993 to 2004 and further to 2014-2015 based on cross-sectional data or the repeated data from 2004 and 2014-2015, suggesting stable psychosocial working conditions for Norwegian doctors. Four major health reforms have been implemented over the last 15 years-the GP list patient scheme in 2001, the free choice of hospital in 2001, the hospital ownership reform in 2002 and the primary/secondary healthcare coordination reform in 2012. These reforms have of course influenced the organisation of doctors' day-to-day practice. One study shows that the perception of professional freedom of speech and professional autonomy among doctors declined from 2000 to $2004 .{ }^{47}$ Another study based on data from 2010 shows that $70 \%$ of doctors experience stress in association with perpetual reorganisations of the national healthcare system, particularly for hospital doctors. ${ }^{48}$ These reforms in the healthcare organisations seem not to be reflected in perceived bullying at work for doctors. Neither do several national antibullying initiatives from 2005, nor does the new Working Environment Act from 2006, ${ }^{49}$ which also includes specific measures against harassment or other improper conduct at work, seem to have influenced the perception of workplace bullying among doctors. This suggests that the amount of perceived bullying is not particularly sensitive to organisational change or protective legislation. Cultural values and traditions in medicine are probably more important. However, a relatively high prevalence of bullying at work in medicine is documented. ${ }^{78}$ An interesting study shows that surgeons view intimidation and harassment in the learning environment as both dysfunctional and functional. ${ }^{45}$

Some important environmental factors that directly or indirectly may generate stress in the healthcare setting did not change during the last two decades. For most doctors in Norway total weekly working hours remained unchanged in the period 1994-2014. ${ }^{25}{ }^{26}$ The satisfaction with various aspects of working conditions, including the amount of responsibility, variation of work, colleagues and fellow workers, opportunities to use own skills, overall job situation, freedom to choose own methods of working, physical work conditions, recognition for good achievements, rate of pay and work hours as measured with the Job Satisfaction Scale ${ }^{29}$ remained relatively stable and high among doctors in Norway. ${ }^{46} 50$

A major personality trait like neuroticism is considered stable in adult life. Subjects scoring high on neuroticism are more likely to perceive situations as threatening. Studies indicate an association between neuroticism and perceiving bullying, although the relationship is complex. ${ }^{20}{ }^{32}$ In our sample, neuroticism was significantly associated with perceived bullying from colleagues or supervisors, suggesting that personality traits, at least neuroticism, may have an impact on the subjective experience of workplace bullying.

\section{Strengths and limitations}

The main strength of our study lies first and foremost in the near representative dataset, making the results generalisable to the entire population of doctors in Norway. ${ }^{2325}{ }^{26}$ Further in the fact that we have data from three different points in time over a period of more than 20 years, including some repeated measures. Similarities in survey methods and comparable items on being subjected to bullying at work are also strengths. The response rates are between $67 \%$ and $78 \%$, which are higher than for most other surveys of the medical profession. ${ }^{26} \mathrm{~A}$ limitation is that we only have self-reported data, although this is considered a plausible methodology. ${ }^{78}$ A further limitation is that the prevalence of perceived bullying at work is based on a single item, and does not meet the gold standard of measuring bullying with a global, checklist-based measure. ${ }^{51}$ However, this practice started after the data collection in 1993 and 2004, and would have been difficult to have incorporated into the survey design in 2014-2015. Other specific elements of workplace bullying like how it occurred (verbal or written by e-post or social media), who the perpetrators were (superiors, doctor colleagues, other personal, patients, relatives or friends of patients) or how long the bullying lasted might be also useful information, but were not obtainable in the present study. 


\section{Policy implications}

Reducing workplace bullying among doctors is important. It can have a positive effect on the doctors' health, the quality of patient care and the work organisation. ${ }^{13}$ Specific attention should be paid to doctors in hospital management position, senior hospital consultants and doctors in academic position, who reported higher prevalence of perceived bullying at work in 2014-2015. Good leadership, social support and improved work environment combined with active workplace interventions are crucial to prevent bullying. ${ }^{19} 3252$ Because intimidation and harassment were found to be a part of medical education, changes in the attitudes towards these negative behaviours are also important. ${ }^{45}$ More recognition and awareness about bullying in medical school and specialist training are instrumental for improving communication and relationship between colleagues.

Acknowledgements The authors wish to thank all doctors who have supported this study by participating in the survey.

Contributors JR and OGA designed the study. JR undertook the literature review, did the statistical analysis and wrote the first draft. OGA made critical revisions. Both authors had full access to all of the data (including statistical reports and tables) and are jointly responsible for the integrity of the data and the accuracy of the data analysis.

Funding This research received no specific grant from any funding agency in the public, commercial or not-for-profit sectors.

Competing interests None declared.

Patient consent Obtained.

Ethics approval According to the Regional Committee for Medical Research Ethics, the study based on "Norwegian Physician Survey —A biannual prospective questionnaire survey to a representative sample of Norwegian physicians" is exempt from review in Norway, cf. $\S \S 4$ of The Act. The project can be implemented without the approval by the Regional Committee for Medical Research Ethics (IRB 0000 1870). Additionally, approval for data protection of the biannual prospective survey among Norwegian doctors was obtained from the Norwegian Social Science Data Service (Reference 19521).

Provenance and peer review Not commissioned; externally peer reviewed.

Data sharing statement The authors may be able to provide on request aggregated data on which the analysis is based. No additional data are available.

Open Access This is an Open Access article distributed in accordance with the Creative Commons Attribution Non Commercial (CC BY-NC 4.0) license, which permits others to distribute, remix, adapt, build upon this work non-commercially, and license their derivative works on different terms, provided the original work is properly cited and the use is non-commercial. See: http://creativecommons.org/ licenses/by-nc/4.0/

(c) Article author(s) (or their employer(s) unless otherwise stated in the text of the article) 2018. All rights reserved. No commercial use is permitted unless otherwise expressly granted.

\section{REFERENCES}

1. Nielsen MB, Magerøy N, Gjerstad J, et al. Workplace bullying and subsequent health problems. Tidsskr Nor Laegeforen 2014:134:1233-8.

2. Reknes I, Pallesen S, Magerøy N, et al. Exposure to bullying behaviors as a predictor of mental health problems among Norwegian nurses: results from the prospective SUSSH-survey. Int J Nurs Stud 2014;51:479-87.

3. Ariza-Montes A, Muniz NM, Montero-Simó MJ, et al. Workplace bullying among healthcare workers. Int J Environ Res Public Health 2013;10:3121-39.

4. Wallace JE, Lemaire JB, Ghali WA. Physician wellness: a missing quality indicator. Lancet 2009;374:1714-21.
5. Eurofound. Sixth european working conditions survey. Luxembourg: Publications Office of the European Union, 2016.

6. Eurofound. Violence and harassment in European workplaces: causes, impacts and policies. Dublin: Publications Office of the European Union, 2015

7. Statistics Norway. Arbeidsmiljø, levekårsundersøkelsen, 2013 [Working environment, survey on living conditions]. 2013. https:// www.ssb.no/arbeid-og-lonn/statistikker/arbmiljo/hvert-3-aar/201407-03 (accessed 7 Sep 2017).

8. Aagestad C, Tynes T, Sterud T, et al. Faktabok om arbeidsmiljø og helse [Factbook on working environment and health]. Oslo: STAMIrapport, 2015.

9. Stebbing J, Mandalia S, Portsmouth S, et al. A questionnaire survey of stress and bullying in doctors undertaking research. Postgrad Med J 2004;80:93-6.

10. Pranjić N, Males-Bilić L, Beganlić A, et al. Mobbing, stress, and work ability index among physicians in Bosnia and Herzegovina: survey study. Croat Med J 2006;47:750-8.

11. Malinauskiene $\mathrm{V}$, Einarsen $\mathrm{S}$. Workplace bullying and post-traumatic stress symptoms among family physicians in Lithuania: an occupation and region specific approach. Int J Occup Med Environ Health 2014;27:919-32.

12. Loerbroks A, Weigl M, Li J, et al. Workplace bullying and depressive symptoms: a prospective study among junior physicians in Germany. J Psychosom Res 2015;78:168-72.

13. Quine $L$. Workplace bullying in junior doctors: questionnaire survey. BMJ 2002;324:878-9.

14. Chadaga AR, Villines D, Krikorian A. Bullying in the american graduate medical education system: a national cross-sectional survey. PLoS One 2016;11:e0150246.

15. Rouse LP, Gallagher-Garza S, Gebhard RE, et al. Workplace bullying among family physicians: a gender focused study. J Womens Health 2016;25:882-8

16. Miedema B, Hamilton R, Lambert-Lanning A, et al. Prevalence of abusive encounters in the workplace of family physicians: a minor, major, or severe problem? Can Fam Physician 2010;56:e101-8.

17. Ling M, Young CJ, Shepherd HL, et al. Workplace bullying in surgery. World J Surg 2016;40:2560-6.

18. Andersen GR, Aasland OG, Fridner A, et al. Harassment among university hospital physicians in four European cities. Results from a cross-sectional study in Norway, Sweden, Iceland and Italy (the HOUPE study). Work 2010;37:99-110.

19. Johan Hauge L, Skogstad A, Einarsen S. Relationships between stressful work environments and bullying: Results of a large representative study. Work Stress 2007;21:220-42.

20. Nielsen MB, Glasø L, Einarsen S. Exposure to workplace harassment and the five factor model of personality: a meta-analysis. Pers Individ Dif 2017;104:195-206.

21. Eriksen GS, Nygreen I, Rudmin FW. Bullying among hospital staff: use of psychometric triage to identify intervention priorities. E-Journal of Applied Psychology 2011;7:26-31.

22. Aasland OG, Falkum E. Legekårsundersøkelsen [Survey on doctors' health, living and working conditions]. Tidsskr nor legeforen 1994;114:3052-8.

23. Aasland OG, Olff M, Falkum E, et al. Health complaints and job stress in Norwegian physicians: the use of an overlapping questionnaire design. Soc Sci Med 1997;45:1615-29.

24. Baltagi BH. Econometric analysis of panel data. England: John Wiley and Sons Chichester, 2005.

25. Rosta J, Aasland OG. Doctors' working hours and time spent on patient care in the period 1994 - 2014. Tidsskr Nor Laegeforen 2016;136:1355-9.

26. Rosta J, Aasland OG. Weekly working hours for Norwegian hospital doctors since 1994 with special attention to postgraduate training, work-home balance and the European working time directive: a panel study. BMJ Open 2014;4:e005704.

27. Normann T, Rønning E. Konflikter, mobbing, trakassering og vold i arbeidslivet [Conflicts, bullying,harassment and violence in working life]. Samfunnsspeilet 2007;4:62-71.

28. Rosta J, Tellnes G, Aasland OG. Differences in sickness absence between self-employed and employed doctors: a cross-sectional study on national sample of Norwegian doctors in 2010. BMC Health Serv Res 2014;14:1-8.

29. Warr P, Cook J, Wall T. Scales for the measurement of some work attitudes and aspects of psychological well-being. $J$ Occup Organ Psychol 1979;52:129-48.

30. Eysenck HJ, Eysenck SBG. The eysenck personality inventory. London: University of London Press, 1964.

31. Cassell MA. Bullying in academe: prevalent, significant, and incessant. Contemp Issues Educ Res 2011;4:33-44. 
32. Nielsen MB, Knardahl S. Is workplace bullying related to the personality traits of victims? A two-year prospective study. Work Stress 2015;29:128-49.

33. Nielsen MB, Einarsen S. Outcomes of exposure to workplace bullying: a meta-analytic review. Work Stress 2012;26:309-32.

34. Einarsen S, Glasø L, Birkeland Nielsen M. Mobbing i arbeidslivet: En litteraturoversikt [Bullying i working life: a literature review]. Tidsskrift for Norsk psykologforening 2008;45:308-17.

35. Tyssen R, Dolatowski FC, Røvik JO, et al. Personality traits and types predict medical school stress: a six-year longitudinal and nationwide study. Med Educ 2007;41:781-7.

36. New in Norway. The Norwegian directorate of integration and diversity: new i norway: work culture. http://www.nyinorge.no/en/Nyi-Norge-velg-sprak/New-in-Norway/Useful-information/Facts-aboutNorway1/Work-culture/ (accessed 4 Sep 2017).

37. OECD. Better Life Index 2016: Life satisfaction. 2016. http://www. oecdbetterlifeindex.org/topics/life-satisfaction/ (accessed 4 May 2017)

38. Eurofound. Fourth european working conditions survey. Luxembourg Office for Official Publications of the European Communities, 2007.

39. Voltmer E, Rosta J, Siegrist J, et al. Job stress and job satisfaction of physicians in private practice: comparison of German and Norwegian physicians. Int Arch Occup Environ Health 2012;85:819-28.

40. Rosta J, Aasland OG. Work hours and self rated health of hospital doctors in Norway and Germany. A comparative study on national samples. BMC Health Serv Res 2011;11:40.

41. Rosta J, Nylenna M, Aasland OG. Job satisfaction among hospital doctors in Norway and Germany. A comparative study on national samples. Scand J Public Health 2009;37:503-8.

42. Tyssen R, Palmer KS, Solberg IB, et al. Physicians' perceptions of quality of care, professional autonomy, and job satisfaction in
Canada, Norway, and the United States. BMC Health Serv Res 2013;13:516

43. Solberg IB, Tómasson K, Aasland O, et al. The impact of economic factors on migration considerations among Icelandic specialist doctors: a cross-sectional study. BMC Health Serv Res 2013;13:524.

44. Hoosen IA. A survey of workplace bullying of psychiatric trainees in the West Midlands. Psychiatr Bull 2004;28:225-7.

45. Musselman LJ, MacRae HM, Reznick RK, et al. 'You learn better under the gun': intimidation and harassment in surgical education. Med Educ 2005;39:926-34.

46. Aasland OG, Rosta J, Nylenna M. Healthcare reforms and job satisfaction among doctors in Norway. Scand J Public Health 2010;38:253-8.

47. Førde R, Aasland OG. Moral distress among Norwegian doctors. $J$ Med Ethics 2008;34:521-5.

48. Førde R, Aasland OG. Moralsk stress og faglig ytringsfrihet blant leger [Moral distress and professional freedom of speech among doctors]. Tidskr nor legeforen 2013;12-13:1310-3.

49. Arbeidsmiljøloven [Working Environment Act]. http://www. arbeidstilsynet.no/binfil/download2.php?tid=92156 (accessed 4 Sep 2017)

50. Rosta J, Aasland O, Nylenna M. Changes in subjective well-being among Norwegian doctors from 2002 to 2012: a panel study. Eur $J$ Public Health 2014(Suppl 1):90.

51. Birkeland Nielsen M, Notelaers G, Einarsen S. Measuring exposure to workplace bullying. CRC Press, 2010:149-74.

52. Einarsen S, Aasland MS, Skogstad A. Destructive leadership behaviour: a definition and conceptual model. Leadersh $Q$ 2007;18:207-16 